Pre-publication draft. To be published in Social Semiotics.

Angela Smith, University of Sunderland, UK

Michael Higgins, University of Strathclyde, UK

\title{
Tough guys and little rocket men: @RealDonaldTrump's Twitter feed and the normalisation of banal masculinity
}

\begin{abstract}
This article looks at discourses of masculinity in the social media performance of US President Donald Trump. The article discusses the implications of these for the normalisation of regressive forms of masculinity in public discourse, where normalisation is the process of co-opting otherwise deviant behaviours by integrating them into institutional practice. The article begins by exploring ways in which Trump's social media performance exhibits the characteristics of "hypermasculinity". The analysis then turns to the everyday expression of traditionally macho masculinity by Trump by conducting a search for tokens of the masculine-gendered nouns "man" and "guy", and using critical discourse analysis to reveal the use of these in exercising gendered forms of judgement. Of particular importance is the informal "guy", through which Trump defines challengers within power-based masculine oppositions. Overall, we find that while the concept of hypermasculinity is useful in describing provocative displays of "bad behaviour" oriented-towards a populist style of leadership, but that Trump routinely produces more banal types of masculine performance that objectify allies and opponents within a gendered hierarchy, and may be said to normalise regressive forms of masculinity within the prevailing political culture.
\end{abstract}

Keywords: Presidential communication; politics and gender; hypermasculinity

\section{Introduction}

Many scholars have identified a shift towards right-wing populism in political leadership, ranging across Italy, Turkey, Finland, the UK and the US. Populism here refers to a political style that strikes a posture against political elites and institutional norms, and presumes to embody and ventriloquize the "voice of the people" (Canovan, 1981). In this pursuit, populism adopts a performative style and demeanour disassociated from the political elites: burnishing anti-establishment credentials through, amongst other things, the display of "bad manners" (Moffitt, 2016: 44). As part of a sustained populist association between manhood and leadership (Zürcher, 2012), claims to anti-political status and a preference for "the ordinary people" are also secured through displays of masculine excess (Spierings et al, 2015). In this article, we examine the usefulness of "hypermasculinity" in understanding Trump's social media performance (Harp, 2019; Kolb, 2019). However, we also look beneath the ostentatious display of masculine "anti-politics" to understand the role that everyday references to gender are used in populist discourse, and acquire a new insight into the more banal use of masculinity in the performance of power. 


\section{Politics and the normalisation of the masculine}

Normalisation is the process by which deviance and malpractice is transformed into an unremarkable part of everyday activity. It is rooted in the study of behavioural and professional norms in largescale organisations, where activities that are demonstrably mistaken or destructive proceed unsanctioned and so become accepted as routine (Vaughan, 2016). We have already noted the attachment to indecorousness that typifies the populist approach to political culture and representation. In particular, research in the area of language study has revealed a deep-rooted and retrograde stereotyping of masculinity and femininity, which is common in most cultures but has come to prominence in contemporary politics (Campus, 2013; Katz, 2013). This involves a polarisation of qualities and attributes that amount to a "two cultures" view of male and female characteristics (see Cameron 2006). In simple terms, it is commonly supposed that feminine stereotypes are characteristic of the private and domestic spheres, while masculine qualities are more appropriate to the public world of work and politics. Following Butler's (1999) conception of gender as inherently contestable, feminist scholars such as Cameron (2006) and Talbot (1986) suggest that these gendered extremes produce invidious systems of representation that disadvantage men as well as women. Moreover, as Mackinnon (2003) and Smith (2016) point out, gender ideals vary from culture to culture and over time. We therefore suggest that gendered categories such as masculinity are best conceptualised as forms of "discourse" (West et al, 1997). When we say this, we offer to treat gender as a type of representation, bound up in the exercise of power. We also submit that ideas of the masculine are asserted through activities of performance, and analysis of these performances linguistic and otherwise - will show something of the tactics and relations of power that are in play.

As a set of discursive relations, the terms of masculinity engage in constant dialogue with other social norms. In addition to the political shift towards populism that motivates this piece, Jeffords (1994) also suggests that the prominent forms of masculinity in US popular film have developed hand-inhand with the dominant political cultures. In the 1980s, therefore, the "hard bodied" heroes reflected the political ideals of the Reagan years gradually transformed into the early-90s cliche of the flawed, heroic male seeking reconciliation with family. However, the advantages of physical strength and the whiff of heroism sustain, and just as Reagan exploited his performative skills and avuncular persona, later actor-turned-politician Arnold Schwarzenegger played knowingly with his "Terminator" image of determined machismo (Drake and Higgins, 2006). The importance of physicality is apparent in contemporary examples too, and just as Russian President Vladimir Putin projects an action man image (Smith, 2016), US President Donald Trump seizes the mantle of "the healthiest president of all time".

Exceptionally, other variations of the masculine ideal can be foregrounded, such as military heroism. For example, the Republican presidential candidate in the 2008 US election, John McCain mitigated concerns over his age and health by emphasising the extent of his experience, and particularly his distinguished war record. McCain's prolonged ordeal as a prisoner in Vietnam was foregrounded in his political marketing as lending him resilience and positioning him as an irrefutably patriotic American (Higgins, 2009). This amounted to a traditional masculinity that presented McCain as "rigid, self-righteous and moralizing [but] manly, courageous and principled" (Kristol, 2008).

Although bereft of McCain's entitlement to military bearing, a more performative claim to combativeness underpins much of Trump's persona. His preferred image is that of a hard-bitten alpha male, amply displayed in the ferocity with which he deals with opponents. Commonly, and as we will see in our discussion of masculinity below, these displays are gendered. Where the targets are women, Trump's comments frequently refer to their physical appearance, even calling upon taboo insults such as "dog". In keeping with the interpretation of these aberrant performances within a 
populist frame, when recorded engaging is sexually explicit descriptions of his attitudes and actions towards women during his 2016 campaign, Trump dismissed his words as "locker room talk"; appropriate to men engaging socially and informally. In ways that accord with what Moffitt (2016: 58) has described above as the "bad manners" of populist politicians, this taboo talk bears the markers of authenticity and spontaneity, with the implied disassociation "from the technocratic style of "politics as usual"'.

We propose to use the following sections of the article to look at the extent to which Trump deploys and reinforces masculine norms. Drawing on the assumptions of "critical discourse analysis" that language use is implicated in the exercise of political power and ideology (Fairclough and Wodak, 1997), we look at the extent to which Trump's social media performances accord with the toxic practices of "hypermasculinity" (Mosher and Serkin, 1984). We use a mixed methods approach. We begin by reviewing the strains of hypermasculinity in Trump's public pronouncements. This is concentrated on Trump's personal Twitter profile, which is distinct from his official Presidential profile but used to convey Presidential statements and initiatives. We then explore how discourses of masculinity operate through outwardly unexceptional references to gender: conducting a search for key terms in Trump's Twitter feed, using Twitter's advance search facility. Word searches are undertaken for Trump's use of "man" and "guy", including relevant material from sequences of tweets in relation to specific topics. A selection of instances are then analysed to see the extent to which gendered descriptions are used tactically, and are mobilised as part of a politics of dominance and exclusion.

\section{Performing hypermasculinity}

As it relates to gendered performances, masculinity should be placed in the context of the rise of gender equality discourses over last half century. From the late 1960s, pre-equality forms of gendered behaviour have increasingly been seen as unusual and deserving of cultural sanction. In terms of how a resurgent hypermasculinity has responded to these, Montgomery et al (2019) identify parallels with the backlash against the institutional promotion of "politically correct" forms of expression, which associated a progressively oriented care over expression with state and regulatory overreach. Similarly, reactive hypermasculinity may potentially be considered as less a return to patriarchy in terms of a sustainable rejection of gender equality, and more a gestural challenge to gender equality as invested in and symbolic of elite establishment thought.

This hypermasculinity is therefore most readily associable with periods when the dominance and form of masculinity itself is under threat. Initially, this was through the achievements of Second Wave Feminism in the 1970s, but in the current climate it is, at least partially, a consequence of economic and governmental breakdown since 2008 , with its consequences for a chiefly male political establishment (see Higgins, 2019). Added to this mix is the success of right-wing reactionary media platforms (Mort, 2012), and, in Trump's particular case, a preponderance of women such as Hillary Clinton and later Nancy Pelosi as political opponents (Harp, 2019). Indeed, Kolb (2019) goes so far as to suggest that the association between "Trump's hypermasculine behaviours" and the discharge of power may disentitle women from future participation in business and political negotiation. In many cases too, this hypermasculinity is articulated with national identity (Zürcher. 2012), mobilising threats of immigration and positioning the forceful man as the defender of national integrity.

In terms of form, hypermasculinity presents an overt rather than banal form of masculinity, based upon exaggerated macho stereotypes. Mosher and Sirkin (1984) direct us to three variables: first, a 
callous sexual attitude towards women; second, and consistent with the "tough guy" tropes we will say more on later, the belief that violence is a manly preserve; and thirdly, an attitude of excitement towards danger.

As Mosher and Sirkin (1984: 151) explain, the first of these - the callous sexualisation of women - is characterised by "a conception of women as dominion and as sexual object who exist as reward for the conquering hero". Whilst the representation of women as "prey" was apparent in the "locker room talk" of Trump's behind-the-scenes recordings with Billy Bush, this is less visible in the publicfacing setting of his post-2016 tweets. However, a survey of Trump's tweets and their surrounding discussion shows an inclination to define women by their attractiveness. The following two examples articulate these attitudes towards women with Trump's performed hostility against an unsympathetic media outlet. Tweets 1 and 2 refer to the NBC weekday news programme, Morning Joe, and one of its hosts, Mika Brzenzinski.

(1) I heard poorly rated @MorningJoe speaks badly of me (don’t watch anymore). Then how come low I.Q. Crazy Mika, along with Psycho Joe, came...

(2) ...to Mar-a-Lago 3 nights in a row around New Year's Eve, and insisted on joining me. She was bleeding badly from a face-lift. I said no! (29 June 2017)

Here we see Trump asserting his alpha-male credentials in a show of personally-directed aggression. This is presented as a hyperbolic attack on the mental health of both presenters ("crazy" and "psycho"), followed by a claim that Mika's facial surgery occasioned Trump's rejection of her and her colleague's company. This both weaponises a common cosmetic surgical procedure, associable with vanity on the part of the victim. and draws material from the private and social realm to be used as an ad hominem component of a public statement. That the event in question takes place in December/January, while the tweet is sent in mid summer, also consistent with the storage and use of illustrative anecdotes from encounters occasioned by Trump's access and privilege.

The second concept highlighted by Mosher and Sirkin (1984: 151) is that violence is manly; indicating raw power and the means to be "dominant in interactions with other men, women and the environment". In common with the items above and with the forms of political machismo identified by Jeffords (1994) in US culture, this foregrounds an iteration of masculine behaviour that is committed to confrontation, either physically or verbally. In Trump's case, this is apparent in two ways: first in his repeated evocations of militaristic discourses of forceful authority against civil disobedience:

(3) Looks like many anti-police agitators in Boston. Police looking tough and smart! Thank you (20 August, 2017)

(4) Great job by all law enforcement officers and Boston Mayor @Marty_Walsh (20 August, 2017)

(5) Our great country has been divided for decades. Sometimes you need protest in order to heal, \& we will heal, \& be stronger than ever before! (20 August, 2017)

Tweets 3, 4 and 5, all from the same day, foreground "tough" as a positive attribute for policing. Yet, even where the third tweet advocates protest as a means to reconciliation, it also expands on the central theme of strength as being the essential factor in sustaining national order ("stronger than ever before!"). 
Second is the maintenance of an antagonistic tone through Trump's rhetoric, where he deploys a subject position of antagonism to defend his position of power against the perceived attack by those who could more conventionally be dealt with through negotiation. This professed refusal to submit to the language of compromise also appears in tweets in which Trump directs belligerent rhetoric against North Korea.

(6) Military solutions are now fully in place, locked and loaded, should North Korea act unwisely. Hopefully Kim Jong Un will find another path! (12 August 2017)

(7) The U.S. have been talking to North Korea, and paying them extortion money, for 25 years. Talking is not the answer! (30 August 2017)

Tweet 6 draws on the discourse of militarism with its use of "locked and loaded". The implicature of Trump's supposed restraint is triggered by "hopefully", before a non-military alternative is mooted. However, the second tweet (7) reformulates incentives back to within a violent frame as "extortion money" before offering a declarative that reignites the implicature of more robust action that appears in the earlier tweet and much of the surrounding commentary.

Other sustained examples of this masculine belligerence can be found where Trump provokes argument with those celebrity "elites" outside of the political establishment. This is clearly linked to his populist campaign slogan, "Make America Great Again", or MAGA, where Trump positions himself as the leviathan of the national interest. A notable example of this arose in late 2016, when a number of NFL players took part in a campaign to draw attention to police prejudice against young black men by choosing to kneel during the national anthem played before each match. Trump picked up on this a year later and rearticulated this to be a strike against America itself, as shown in two Tweets from 24 September 2017:

(8) Sports fans should never condone players that do not stand proud for their National Anthem or their Country. NFL should change policy! (24 September, 2017)

(9) Courageous Patriots have fought and died for our great American Flag --- we MUST honor and respect it! MAKE AMERICA GREAT AGAIN! (24 September, 2017)

Expressed within a modality of obligation ("should now", "must honour"), this contributes to a national-popular rhetoric dedicated to Trump's expression of American greatness. The MAGA theme as an implied consensus is thus directed to criticise a peaceful protest that is not connected with a national identity that accords with Trump's vision. Throughout this initial engagement with the protests, Trump retweeted the views of others who shared his interpretation, including Donna Warren who initiated an argument to boycott the NFL. This is a line that Trump seizes upon:

(10) Great solidarity for our National Anthem and for our Country. Standing with locked arms is good, kneeling is not acceptable. Bad ratings!

(11) NFL attendance and ratings are WAY DOWN. Boring games yes, but many stay away because they love our country. League should back U.S.

(12) If NFL fans refuse to go to games until players stop disrespecting our Flag and Country, you will see change take place fast. Fire or suspend! 
Trump's hostility to the protest is thus articulated as a defence of the nation, and draws on an unattributed claim on declining NFL attendances to mobilise a populist trope that he speaks for "the people". Thus protest is seen as threatening and destructive, factors Trump emphasises in the third Tweet here with the imperative: "Fire or suspend!", aimed presumably at the owners of the individual NFL teams. To some degree, Trump was successful in this as the most high profile instigator of the peaceful protest, Colin Kaepernick, was dropped by the 49ers at the start of 2017 and has not played professionally since.

The third concept Mosher and Sirkin (1984) point to as the hypermasculine appetite for danger. Trump's relish for moments of crisis or disaster can be seen in his Tweets relating to Hurricane Harvey in August 2017, where the approaching danger was heralded not with calls for action (as seen in the tweets of Obama at this time), but with the heavy-handed use of capitalisation and exclamation points (used in this context to indicate a raised voice) expressing the drama of the storm. The following Tweets were all were sent in rapid succession on 28 August 2017:

HISTORIC rainfall in Houston, and all over Texas. Floods are unprecedented and MORE rain coming, Spirit of the people is incredible. Thanks! (28 August, 2017)

(14) MAJOR rescue operations underway! (28 August, 2017)

(15) Going to a Cabinet Meeting (tele-conference) at 11:00 A.M. on \#Harvey. Even experts said they've never seen one like this! (28 August, 2017)

(16) WOW- Now expert are calling \#Harvey a once in 500 year flood! We have an all out effort going, and going well! (28 August, 2017)

The use of capitals in tweets 12, 14 and 16 all hint at excitement rather than concern, the first two amplifying the importance and the third producing a colloquial and overblown declaration of astonishment ("HISTORIC", "MAJOR". "WOW"). This is all reinforced by the use of exclamation points in all four Tweets. Unnamed experts are cited to support the drama of the situation in Tweets 15 and 16, and the status of the hurricane as a social media event is enhanced by the use of a hashtag for its name "\#Harvey".

We can see that there is indeed scope for tracking the characteristics of hypermasculinity in Trump's performance on Twitter. As well as enacting aggressiveness and expressing an objectification of women, this is a form of engagement that is notable in its manner of expressing authority by drawing upon a national-popular consensus, in which Trump assumes the role of guardian and arbiter. Whilst during the 2016 presidential campaign and in the early months of his presidency these hypermasculine performances drew criticism and became news stories in their own right, these criticism ceased to gather traction and soon this performance became accepted as a routine enactment of an individual style. However, we will now look at the more banal expression of masculine power and the its normalisation.

\section{What is a Man? Great men, dead men and rocket men}

Having detected strains of hypermasculine conduct in Trump's Twitter feed, we now therefore turn to how he uses more routine references to maleness and incorporates them into a style of public discourse. To do this, we look first at the gendered noun "man". We should say that while instances of its use follow significant patterns, "man" appears relatively infrequently in Trump's Twitter feed: the Twitter search reveals 66 occurrences. We conduct an initial exploratory content analysis of these 
references, assessing whether a negative or positive attitude is taken towards the subject. While the sample is not sufficient to draw wider conclusions in content analysis terms, the majority of these references -50 of the total - use "man" in a positive tone, with 15 taking a negative tone, along with 1 ("Call your Dem Senator or Congresswoman/man. Tell them to get it done!, Jan 12, 2019) categorised as neutral.

As a gendered noun, "man" appears in a variety of ways. In keeping with Crane et al (2013)'s observation that "man" tends to connote a bearer of responsibility and authority, it commonly invokes a status as a comparatively formal designation, by placing the subjects within an institutional context. This is consistent with the use of "man" by Trump is in description of the personal qualities of an individual. The following tweet is a typical example:

Representative Devin Nunes, a man of tremendous courage and grit, may someday be recognized as a Great American Hero for what he has exposed and what he has had to endure! (February 5, 2018)

In this instance, "man" is used to express a shift from the specific statesman to the universal attributes he enjoys ("courage and grit"). This elaboration on an institutional theme, the qualities of the individual in office, focuses on roles and personal achievements. This also enables "man" to be deployed in activities of self-definition, as the following examples that Trump has retweeted show: ....unbelievably lucky to have him and I'm just awed at how well they've done. It's all the Trump magic - Trump is the magic man. Incredible, he's got the entire media against him, attacking him every day, and he pulls out these enormous wins." Ben Stein, "The Capitalist Code" (November 25, 2018).

(19) General Anthony Tata: "President Trump is a man of his word \& he said he was going to be tough on the Border, and he is tough on the Border. He has rightfully strengthened the Border in the face of an unprecedented threat. It's the right move by President Trump." Thanks General! (November 25, 2018).

In Trump's own Tweets, we find this pattern in which Trump's own policy attributes are emphasised is repeated: ....I am a Tariff Man. When people or countries come in to raid the great wealth of our Nation, I want them to pay for the privilege of doing so. It will always be the best way to max out our economic power. We are right now taking in \$billions in Tariffs. MAKE AMERICA RICH AGAIN (4 December, 2018) ....a man who is considered by many to be the President with the most successful first two years in history, especially when he has done nothing wrong and impeachment is for "high crimes and misdemeanors"? (March 13, 2019)

In a pattern of tactical conviviality we return to in the conclusion, the Tweets 18 and 19 are offered as direct quotes from others, presented by Trump as evidence of the regard in which he is held. In a likely-unconscious internalisation of the classical notion of "man" as driver of progress (Sennett, 2002), both quotes draw upon classical notions of "man" as a potential instrument of purity and 
greatness: man as a conduit for magic and truth respectively, able to be defined by his qualities and actions. This presentation of the self as agent of a greater cause is also apparent in own Trump's claim to the status of "Tariff Man", hinting at a superhero lexicon that will re-emerge later, and still more in the third-person description of the self as the object of the praise of others ("considered by many").

This alliance between institutional standing, the formal expression of gender, and personal character is perhaps most apparent in those tweets offering tribute to those recently deceased.

(22) Deepest sympathies to Congresswoman Debbie Dingell and the entire family of John Dingell. Longest serving Congressman in Country's history which, if people understand politics, means he was very smart. A great reputation and highly respected man (February 8, 2019)

(23) I was a big fan of Frank Robinson, both as a great player and man. He was the first African American manager in baseball and was highly respected at everything he did. He will he missed! (February 8, 2019)

(24) Looking forward to being with the Bush family. This is not a funeral, this is a day of celebration for a great man who has led a long and distinguished life. He will be missed! (December 5, 2018).

In ways that produce parallels with the man-as-agent discourses above, these tweets submit to the lexicon of tribute - "long and distinguished", "highly respected - and collocate "man" with such adjectives as "great" to produce associations between those described and public standing. However, even as man has the potential for good, defined by Trump's assessment of their reputation, a minority of negative instances portray the potential on manhood as squandered:

....Foundation be listed at the top of the Report? Will the scathing document written about Lyin' James Comey, by the man in charge of the case, Rod Rosenstein (who also signed the FISA Warrant), be a big part of the Report? Isn't Rod therefore totally conflicted? (December 23, 2017)

(26) Lebron James was just interviewed by the dumbest man on television, Don Lemon. He made Lebron look smart, which isn't easy to do. I like Mike! (August 3, 2018).

In keeping with what we have identified as the relative lexical formality of "man", both these tweets judge their subjects in terms of institutional competence. Tweet 25 situates "man" firmly within the administrative field - "the man in charge of the case" - before undermining the associated status in the elaborated "totally conflicted". Tweet 26 is sustains this turn to affected informality, juxtaposing the formality of man with the US slang adjective "dumbest", itself juxtaposed with Trump's favoured positive attribute "smart". 
As will become still more apparent in the section that follows, Trump makes frequent use of adjacency pairs in the formulation of descriptions. We see this fixation with definitional description in "Lyin' James Comey" (25). The following tweets repeat Trump's then-preferred nickname for the North Korean President, Kim Jong-Un.

Being nice to Rocket Man hasn't worked in 25 years, why would it work now? Clinton failed, Bush failed, and Obama failed. I won't fail (October 1, 2017)

(28) I told Rex Tillerson, our wonderful Secretary of State, that he is wasting his time trying to negotiate with Little Rocket Man... (24 November, 2017)

(29) Sanctions and "other" pressures are beginning to have a big impact on North Korea. Soldiers are dangerously fleeing to South Korea. Rocket man now wants to talk to South Korea for first time. Perhaps that is good news, perhaps not - we will see! (January 2, 2018)

This name is motivated by a particular representational purpose: to associate Jong-Un with a project to develop intercontinental nuclear missiles. There are easily recognisable parallels here with his frequent use of "Crooked Hillary", a description coined to associate a political rival with allegations of malpractice. While using an elaboration of "man" rather than the name of his opponent may be motivated by the likelihood of name recognition, it nonetheless sustains the use of "man" within a judgemental realm associated with institutional authority. The contrivance of this nickname for a political adversary is drawing on the superhero comic convention established for traditionally masculine characters such as Super Man, Spider Man, Bat Man, etc. However, the diminutive adjective "little" overrides the power of "Rocket" and instead serves to undermine the established semantic prosody to produce a less obliging one, in the same way as "girlie man" was used in the late 1980s by hyper-macho Arnold Schwarzenegger to attack George H. Bush's presidential opponent.

Overall, while clearly gendered in the everyday usage, references to "man" are also normative. "Man" is used to exercise judgement, in praising service and steadfastness on the one hand, and as a contrastive gibe to ridicule fecklessness and childishness, on the other. Characteristic of the use of "man" is the setting of institutional authority, within which conduct and reputability is judged: heroic on the part of Trump, laudable in those in whom he approves, and comically disempowering in the case of Jong-Un.

\section{Guys: great, amazing, nice and tough}

Having examined Trump's use of the relative formal gendered noun "man", we now undertake a similar search for the use of the less formal designation "guy" in Trump's tweets. This use of "guy" is partly rooted in playful reference to a man of unthreateningly grotesque appearance, as in Hughes' $19^{\text {th }}$ century novel Tom Brown at Oxford's "You wonderful old Guy. Where did you pick up that toggery?" (Hughes, 1864: 544). This is consistent with such more recent analyses as Halbert and Latimer's (1994: 305) examples of "guy" in sports commentary used to anchor discussions of showmanship. "Guy" is therefore a less formal and more layered description than "man". 
Our search for "guy" in Trump's Twitter feed produces 79 results, with a more even division between its deployment in positive (at 46) as against negative (at 33) descriptions. In keeping with its colloquial associations, its use offers the potential to shift tone from one that retains traces of a formal lexicon, to one that is overtly casual. This lends a more spontaneous gloss, even, as the second tweet shows, in the more ritualistic act of paying tribute.

(30) Rush Limbaugh is great, tells it as he sees it---really honorable guy! Thanks Rush! \#Trump2016 (January 22, 2016)

(31) Have a good chance to win Texas on Tuesday. Cruz is a nasty guy, not one Senate endorsement and, despite talk, gets nothing done. Loser! (February 26, 2016)

(32) I met Prince on numerous occasions. He was an amazing talent and wonderful guy. He will be greatly missed! (April 22, 2016)

This selection of tweets shows the descriptive latitude that the relatively informal "guy" enjoys in Trump's expressive universe ("nasty", "amazing", "honourable"). They also range in modes of address, such that the Rush Limbaugh tweet includes thanks expressed directly to the subject. This malleable frame is also apparent in the tribute tweet about the musician Prince, where the more casual descriptor is warranted by Trump's opening claim of intimacy.

In terms of its contribution to Trump's overall rhetoric style, "guy" also presents the opportunity for the repetition of adjacency pairs, the most prominent of which is "great", as tweets 33-36 show:

(33) So nice to get an endorsement from the founder and owner of Pizza Ranch in Iowa! A great guy and great places! \#CaucusForTrump (January 31, 2016).

(34) Great being with the National Champion Clemson Tigers last night at the White House. Because of the Shutdown I served them massive amounts of Fast Food (I paid), over 1000 hamburgers etc. Within one hour, it was all gone. Great guys and big eaters! (January 15, 2019)

Watch Coach Mike Ditka- a great guy and supporter tonight at 8pmE on \#WattersWorldwith@jessebwatters @FoxNews (November 3, 2016).

@GeraldoRivera Thank you Geraldo for your nice words on @oreillyfactor tonight. You are a true champion! Thank @ericbolling - great guy! (January 15, 2016).

(37) Honored to have received the endorsement of Lou Holtz - a great guy! \#INPrimary \#Trump2016 (May 2, 2016) 
The use of such repetition is central to Trump's rhetorical style on Twitter, where he reuses stock phrases and exclamations, such as "loser" and "sad" (cf. Oborne, 2017). In this case, the description is applied while referring to the support of the individuals described (Ditka, Rivera and Holt). The use of "great guy" articulates Trump's personal endorsement with a gendered assertion of casual male intimacy, combining familiarity with an on-going assertion of Trump's conviviality.

In a similar shift in tone to the tribute to Prince (tweet 32), the last tweet illustrates the utility of "guy" in enabling a switch from the political act of thanking for an endorsement, to an informal comment on character in "a great guy" (tweet 37).

However, we noted in our discussion on hypermasculinity above that Trump used Twitter as a medium of attack. When turned to a negative use, "guy" also appears alongside a range of accompanying descriptions, to various effects:

(38) I authorized Zero access to White House (actually turned him down many times) for author of phony book! I never spoke to him for book. Full of lies, misrepresentations and sources that don't exist. Look at this guy's past and watch what happens to him and Sloppy Steve! (January 4, 2018)

(39) How low has President Obama gone to tapp my phones during the very sacred election process. This is Nixon/Watergate. Bad (or sick) guy! (March 4, 2017).

(40) With that being said, I have personally directed the fix to the unmasking process since taking office and today's vote is about foreign surveillance of foreign bad guys on foreign land. We need it! Get smart! (January 11, 2018).

The first two of these tweets allege institutional malpractice, and the informal designation offers a contrast to the institutional setting we see in the examples of "man" discussed above. The "bad guys" designation drew upon a standing theme in Trump's public speech using "bad" in an elaborated description, with "bad hombres" included in a discussion of immigrants.

Contrasting with the mainly institutional connotations of "man", and in situating the subject within a non-political lexicon, "guy" also offers the scope for a more casual dismissal of a political opponent, as the first two of these examples show:

(41) North Korea has just launched another missile. Does this guy have anything better to do with his life? Hard to believe that South Korea..... (July 3, 2017)

(42) I never asked Comey for Personal Loyalty. I hardly even knew this guy. Just another of his many lies. His "memos" are self serving and FAKE! (April 16, 2018) 
(43) "@AnyoneTennis: @timkaine Cannot believe how often the moderator interrupts \#Pence vs the other guy...so obvious @FoxNews" So true! (October 4, 2016).

Even as the tweets above weaponise the informality of guy to alienate the individuals from their formal positions through trivialisation, the third tweet sees the belittling function of the term intensify, as it is used to supplant the institutional standing of Pence's opponent, Vice-President Biden, by pretending a dismissive non-recognition.

\section{Nice guys are failed guys}

So far we have seen how "guy" produces a rhetorical alternative to man, in which Trump can either claim intimacy or alienate his opponents from their positions of political standing. However, the judgements associated with "guy" are divided more deeply, the first element of which is visible in its collocation with "nice". This entails a strategy which, in Baxter's (2014: 6) terms, amounts to "corrective double-voicing". Such a tactic allows Trump to anticipate criticism that he is being inconsistent in his views about others in whom he has previously invested praised. In other words, he ameliorates his criticism by producing an apparent compliment.

(44) Watching John Kasich being interviewed - acting so innocent and like such a nice guy. Remember him in second debate, until I put him down (January 15, 2016). @BernardGoldberg was not good tonight on @oreillyfactor. He just doesn't know about winning! But he is a nice guy (December 10, 2015).

....them richer. Their network is highly overrated, I have beaten them at every turn. They want to protect their companies outside the U.S. from being taxed, I'm for America First \& the American Worker - a puppet for no one. Two nice guys with bad ideas. Make America Great Again! (July 31, 2018)

So funny! I just checked out Fake News CNN, for the first time in a long time (they are dying in the ratings), to see if they covered my takedown yesterday of Jim Acosta (actually a nice guy). They didn't! But they did say I already lost in my meeting with Putin. Fake News...... (July 14, 2018).

@theblaze: Donald Trump unleashes verbal assault on "nice guy" Ted Cruz: http:/www.theblaze.com/stories/2015/12/12/donald-trump-unleashes-verbal-assaulton-nice-guy-ted-cruz/..."

(49)@MachadoKirk:@StrengthenTheUS@realDonaldTrump Carson is not a nice guy. He knows his SuperPAC throws Mud on Trump 24/7 \#ActingMeek" (October 24, 2015) 
Such that the first three are political opponents that Trump portrays as having been trounced by him, and the fourth a "failing" media network, these collocations of "nice" and "guy" amount to wellmeaning but weak. This has the strains of the early meanings of "nice", where the term would be used for one that was a simple person or fool, with examples of including Chaucer's reference to "any fool or nyce" in The Romance of the Rose. In terms of current usage, "nice guy" resembles Crane et al's (2013) description of "sweet guy" invoking strains of feminised weakness. Consistent with this lexical heritage, tweets 45 and 46 equate niceness with ineffectiveness, setting the term in contrast with "winning" and alongside "bad ideas" respectively. Also in the context of the negative implications of nice in Trump's lexicon, the last two (tweets 48 and 49) portray attempts to appear nice as evidence of deceit on the part of political opponents Ted Cruz and Ben Carson. This equates the pretence of niceness with unmanly dishonesty, in the case of Cruz with Trump disassociating himself from the designation "nice guy" in ironic quotation marks.

\section{So-called tough guys}

An outwardly contrasting but related form of judgement relates to the collocation of guys with tough. Harmer et al (2017) suggest "tough" as a means of deploying masculinity in the assessment of personal political performance. In such a context, "tough" is taken to mean resilient and capable of prevailing in political disputes. However, this immediate collocation of "tough guy" is reserved for the ironic description of Trump's political enemies:

(50) Weak and low energy @JebBush, whose campaign is a disaster, is now doing ads against me where he tries to look like a tough guy (February 24, 2016).

@JebBush just took millions of \$'s in special interest money to look like a tough guy. Will never work! (December 22, 2015)

(52)@@ahernandez85a:@realdonaldtrump Mr Tough Guy Romney should be backing Trump like Trump backed him last time \#NoLoyalty" (February 24, 2016)

(53) Crazy Joe Biden is trying to act like a tough guy. Actually, he is weak, both mentally and physically, and yet he threatens me, for the second time, with physical assault. He doesn't know me, but he would go down fast and hard, crying all the way. Don't threaten people Joe! (March 22, 2018)

(54)@@conservativevin: @ahernandez85a Romney should have been a tough guy with Obama. He cowered and lost. BADLY! He's not relevant!"

In keeping with their use of "guy" to suggest the adoption of a thin veneer of masculinity, these tweets foreground the language of appearance and performance - "to look", "to act" - or the adoption of a persona ("Mr Tough Guy"). The condemned activities amount to attempting to compete in conventional masculine terms, in a manner in which their failure is itself gendered. On each occasion, however, the aspirations of the target of "tough guy" is to undertake a task more appropriate to the manly endeavours of Trump himself. This is expressed as campaign effort and expenditure (in the case of Jeb Bush) first loyalty and then willingness to engage robustly with Barack Obama (in the 
case of Mitt Romney) and combative competition (in the case of Joe Biden). The implication of these together is that, through his abilities and successes, Trump is demonstrably the real tough guy, against whom pretenders are judged. Politics is offered as dependent less on wisdom and dedication, than on the successful enactment of Trump's unmatched demonstration of the masculine ideal.

\section{Exclusion and inclusion: normalising hypermasculinity}

It is important to acknowledge that Trump's hypermasculine Twitter style is the subject of critique. References to women in demeaning terms rarely pass without almost immediate condemnation. Harp (2019: 42) stresses this "hypermasculine" component in Trump's 2016 election campaign, but also expresses "hope that the troublesome aspects of this dominant masculinity and binary gender constructs are fading". Indeed, in this sense, the hypermasculine component of his Twitter performance has become an essential part of Trump's enactment of "bad manners" in order to emphasise his non-establishment credentials (Moffitt, 2016: 57). However, we also suggest that Trump's misogynistic use of gender takes a more banal form, and we see this in the on-going moblilisation of a language of excessive masculinity in order to diminish the standing of political opponents. This is less the use of gendered insults, and more the deployment of a lexicon of gender distinction in assessing such virtues as masculine courage, set against weakness; and of success set against defeat.

However, the communicative purchase of Trump's Tweets rests on the twin pillars of marginalisation and inclusion. On the one hand, we can easily identify an aggressive masculine performance of symbolic violence towards others, and a setting apart of the marginal coupled with a trivialisation and emasculation of opponents. Yet, we have also shown how this masculine performance is manifest in the construction of an approved group of acolytes. The most straightforward and platform-specific method of inclusion and approval is to retweet an approved contribution. We see above how Trump retweets others as courtiers producing appropriate forms of praise, and uses gendered designations to heap praise upon others. What is also clear, therefore, is the dialogic quality of Trump's use of gender. To invoke the "participation framework" proposed by Montgomery et al (2019), the discourse is doubly-articulated towards the individual to whom Trump wishes to issue the commendation - or on other occasions condemnation - while extending the dialogue to his followers and supporters.

These may be described in the terms that Krzyzanowski and Ledin (2017) call "borderline discourses" turned towards the conviviality of an implied political ingroup, itself articulated with a populist masculinity itself invested in a national-popular. Even within the broader context of a masculine politics, Trump's aggressive and hypermasculine performances often present themselves as alien to the civil discourses of the formal political realm. In this sense, Trump's tweets amount to what Krzyzanowski and Ledin (2017) refer to as "border raids", conducted to gather tropes, themes and modes of expression designed to offend dominant political sensibilities. From the moments of their enactment, the more extreme of Trump's Tweets produce energy through their status as "bad behaviour", sustaining Trump's place outside of the political mainstream (Moffitt, 2016). However, sustained discourses of gender difference and objectification pervade even the ritualistic and banal components of Trump's Twitter feed. Thus, Trump's rejection of traditional norms of accountability and truth (Montgomery, 2017; Higgins, 2019) extends to an unrelenting refusal of the norms and behaviours of gender equality. Even as Trump's social media conduct sits within a broader performative idiolect, he forces the expansion of the expressive latitude accorded to political elites. In his sustained and unmodified use of these forms of masculinity, Trump now longer shocks. To this end, we suggest that this refusal of the political decorousness expected of senior office has been normalised, and the void filled with the language of convivial patronage, prejudice and exclusion. 


\section{References}

Baxter, Judith. 2014. Double-Voicing at Work: Power, Gender and Linguistic Expertise. Basingstoke: Palgrave.

Butler, Judith. 1999. Gender Trouble: Feminism and the Subversion of Identity. New York: Routledge.

Cameron, Deborah. 2006. "Theorising the female voice in public contexts" in Speaking Out: the Female Voice in Public Context, edited by Judith Baxter, 1-20, Basingstoke: Palgrave Macmillan.

Campus, Donatella. 2013. Women Political Leaders and the Media. Basingstoke: Palgrave.

Canovan, Margaret. 1981. Populism. London: Junction.

Crane, Betsy, Angela Towne and Jesse P. Crane-Seeber. 2013. "The four boxes of gendered sexuality: a lesson plan for teaching about the history and effects of gendered sexuality", American Journal of Sexuality Education 8 (4): 274-305.

Drake, Philip and Michael Higgins. 2006. "I'm a celebrity, get me into politics: the political celebrity and the celebrity politician", Framing Celebrity: New Directions in Celebrity Culture, edited by Su Holmes and Sean Redmond, 87-100. London: Routledge.

Fairclough, Norman and Ruth Wodak. 1997. "Critical discourse analysis", in Discourse as Social Interaction, edited by Teun A. van Dijk, 258-284, London: Sage.

Halbert, Christy and Melissa Latimer. 1994. “'Battling' gendered language: an analysis of language used by sports commentators in a televised co-ed tennis competition", Sociology of Sport Journal 11: 298-308.

Harp, Dustin. 2019. Gender in the 2016 Presidential Election: Trump, Clinton and Media Discourse. London: Routledge.

Hall Jamieson, Kathleen. 1996. Packaging the Presidency: a History and Criticism of Presidential Campaign Advertising ( $3^{\text {rd }}$ edition). New York: Oxford University Press.

Harmer, Emily, Heather Savigny and Orlando Ward. 2017. “'Are you tough enough?' Performing gender in the UK leadership debates 2015", Media, Culture \& Society 39 (7): 960-975. 
Higgins, Michael. 2009, "Populism and security in political speechmaking: the 2008 US Presidential campaign", in Media, Religion and Conflict, edited by Lee Marsden and Heather Savigny, 129-144, Farnham: Ashgate.

Higgins, Michael. 2019. “The Donald: media, celebrity, authenticity and accountability", in Trump's Media War, edited by Catherine Happer, Andrew Hoskins and William Merrin, 129-142, Basingstoke: Palgrave Macmillan.

Hughes, Thomas. 1864. Tom Brown at Oxford. London: George Routledge.

Jeffords, Susan. 1994. Hard Bodies: Hollywood Masculinity in the Reagan Era. New Brunswick: Rutgers University Press.

Kolb, Deborah M. 2019. "Her place at the table: gender and negotiation after Trump", Negotiation Journal 35 (1): 185-189.

Kristol, William. 2008. “Thoroughly unmodern McCain”. New York Times, 21 January.

Krzyzanowski, Michal and Per Ledin. 2017. "Uncivility on the web: populism and/in the borderline discourses of exclusion", Journal of Language and Politics 16 (4): 566-581.

Mackinnon, Kenneth. 2003. Representing Men: Maleness and Masculinity in the Media. London: Hodder Arnold.

Moffitt, Benjamin. 2016. The Global Rise of Populism: Performance, Political Style and Representation. Stanford: Stanford University Press.

Montgomery, Martin. 2017. "Post-truth politics? Authenticity, populism and the electoral discourses of Donald Trump", Journal of Language \& Politics 16 (4): 619-639.

Montgomery, Martin, Michael Higgins and Angela Smith. 2019. "Political offensiveness in the mediated public sphere: the performative play of alignments", in Media and the Politics of Offence, edited by Anne Graefer, 23-46, Basingstoke: Palgrave Macmillan.

Mort, Sébastian. 2012. "Tailoring dissent on the airwaves: the role of conservative talk radio in the right-wing insurgence of 2010", New Political Science 34 (4): 484-505. 
Mosher, Donald L. and Mark Serkin. 1984. "Measuring a macho personality constellation", Journal of Research in Personality 18 (2): 150-163.

Oborne, Peter and Tom Roberts. 2017. How Trump Thinks. London: Head of Zeus.

Sennett, Richard. 2002. The Fall of Public Man (revised edition). Harmondsworth: Penguin.

Smith, Angela. 2016. "Mediated political masculinities: the commander-in-chief vs the new man. Social Semiotics, 26 (1): 94-110.

Spierings, Niels, Andrej Zaslove, Liza M. Mügge and Sarah L. de Lange. 2015 "Gender and populist radical-right politics: an introduction", Patterns of Prejudice 49 (1-2): 3-15.

Talbot, Mary. 1998. Language and Gender: an Introduction. Cambridge: Polity.

Van Zoonen, Liesbet. 1994. Feminist Media Studies. London: Sage.

Vaughan, Diane. 2016. The Challenger Launch Decision: Risky Technology, Culture and Deviance at NASA (revised edition). Chicago: Chicago University Press.

West, Candace, Michelle M. Lazar and Cheris Kramarae. 1997. "Gender in discourse", in Discourse as Social Interaction, edited by Teun A. Van Dijk. 119-143, London: Sage.

Zürcher, Erik-Jan. 2012. "In the name of the father, the teacher and the hero", in Political Leadership, Nations and Charisma, edited by Vivian Ibrahim and Margit Wunsch, 129-142, London: Routledge. 